\title{
Numerical Investigation on Composite Mono-Leaf Springs Reinforced with Polyurethane/Carbon Nanotubes (PU/CNTs) Nanoweb Interlayers
}

\author{
Bertan Beylergil \\ Department of Mechanical Engineering, Faculty of Engineering, Alanya Alaaddin Keykubat University, Alanya, \\ Antalya, Turkey \\ *bertan.beylergil@alanya.edu.tr
}

Received: 25 August 2018

Accepted: 12 December 2019

DOI: $10.18466 /$ cbayarfbe. 455110

\begin{abstract}
Composite materials have been widely used in automobile industry to reduce vehicle weight and cut $\mathrm{CO}_{2}$ emissions. With the rapid advancement of nanotechnology, it is now possible to improve the mechanical performance of these materials more than ever before. In this study, mechanical behavior of carbon fiber/epoxy (CF/EP) composite mono-leaf springs reinforced with polyurethane/carbon nanotubes (PU/CNTs) nanoweb interlayers was investigated numerically. The effect of hybridization in composite leaf springs was revealed. The numerical analyses were carried by using ANSYS Workbench with ACP module. The numerical verification of the finite element model was carried out by comparing numerical results against analytical calculations. Then, the verified FE model was extended to this study. The numerical results showed that the stiffness of the composite wave springs could be increased by $18 \%$ with the addition of PU/CNTs nanofibers (CNT content: 5 wt. \%) in the interlaminar region without weight and thickness increase. It was also observed that the natural frequency values increased by $8 \%$ (CNT content: $5 \mathrm{wt} . \%)$ after the addition of these nanofibers.
\end{abstract}

Keywords: Leaf spring, Composite, Stiffness, Polyurethane, Carbon nanotubes, Interlayers.

\section{Introduction}

Fiber reinforced composites have been extensively used in automobile, defense and aerospace industries due to their unique advantages such as high strength and stiffness at low weight, good corrosion resistance and fatigue properties [1-3].

Leaf springs are mainly used in suspension systems to absorb shock loads occurred due to road irregularities in heavy and light duty commercial vehicles. They also withstand lateral loads, brake torque, driving torque as well as shock loads. Due to their high elastic strain energy storage capacity, composite materials offer a perfect solution to reduce the overall weight of an automobile without stiffness loss and reduction in loadbearing capacity $[4,5]$. Therefore, the increased attention has been paid to the replacement of steel leaf springs with composite ones by the researchers. In literature, there are many experimental and numerical studies about composite leaf springs. Recently, Ashwini and Mohan Rao [6] systematically reviewed these studies on this topic.

The use of thermoplastic electrospun nanofibers in the interlaminar region of composites is one of the most promising techniques due to some unique advantages such as improved delamination resistance (up to 3 times depending on the polymer type and nanofiber areal weight density) with uncompromised in-plane mechanical properties, no additional weight/thickness and unchanged resin viscosity [7-10]. The first commercial suppliers of electrospun nanofiber interlayers are on the market and the transition of these nano interlayers into commercial products has already started. Today, it is possible to obtain different types of thermoplastic nanowebs in the market. The first real-life application of nanointerleaved composites can be seen in a carbon fiber/epoxy fishing rod manufactured by Kilwell Sports Ltd. The bending strength of these fishing rods was almost $100 \%$ higher than those of the old-fashioned ones [11]. Further research is needed to understand the effects of nano-interleaving technique for the other possible structural applications.

In this study, for the first time, the effects of PU/CNTs nanoweb interlayers (CNTs content: 1 and 5 wt. \%) on the mechanical behavior of carbon fiber/epoxy composite leaf springs were investigated by using ANSYS 16.2 software package. It is aimed to make a 
unique contribution to the existing literature and present a new win-win solution to enhance the stiffness and natural frequencies of existing composite leaf springs.

\section{Problem definition and analytical calculations}

Figure 1 shows the mono-leaf spring considered in this study. The dimensions of the mono-leaf spring were given in Table 1.
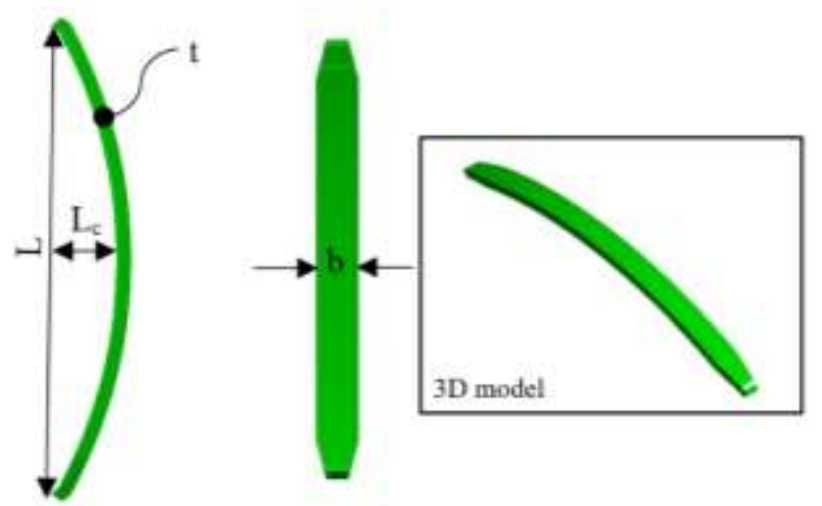

Figure 1. Dimensions and 3D model of the mono-leaf spring.

The maximum displacement of a steel-made mono-leaf spring under the applied load $(P)$ and the stress can be calculated by using Equations (2.1) and (2.2) respectively [12].

$$
\begin{gathered}
\delta_{\max }=\frac{3 P L^{3}}{4 E b t^{3}\left(3 n_{m}+2 n_{g}\right)} \\
\sigma_{\text {max }}=\frac{3 P L}{2 n_{m} b t^{2}}
\end{gathered}
$$

where $L, b, t$ are the length, width and thickness of the mono-leaf spring respectively. $n_{m}$ and $n_{g}$ are the number of master leaf and the number of graduated-length leaves, respectively $\left(n_{m}=1\right.$ and $n_{g}=0$ for mono-leaf spring). The elastic modulus and the density of the steel was assumed as $200 \mathrm{GPa}$ and $7850 \mathrm{~kg} / \mathrm{m}^{3}$, respectively.

Figure 2 shows the load-displacement characteristics of steel-made leaf spring obtained by using Equations (2.1). The corresponding normal stress values were also shown in Figure 2. The stiffness of the steel-made leaf spring was determined as $749.5 \mathrm{~N} / \mathrm{mm}$.

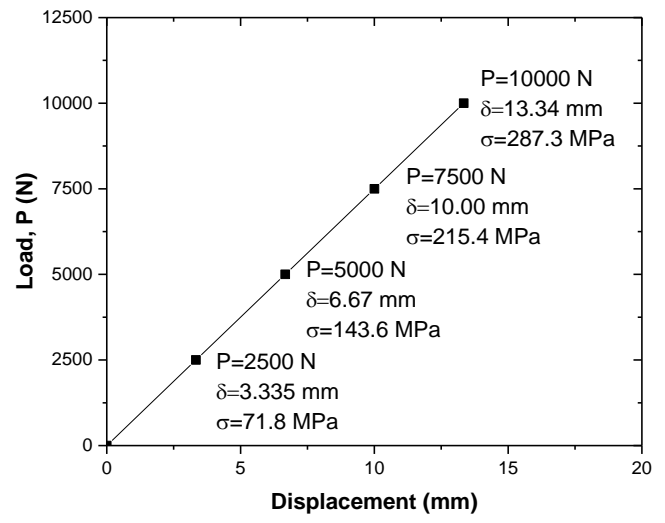

Figure 2. Load-displacement characteristics of steelmade composite leaf spring.

\section{Finite element modeling of steel mono-leaf spring and numerical verification}

In order to verify the finite element model used in this study, steel-made mono-leaf spring were analyzed by using ANSYS Workbench. The numerical results were compared with the analytical calculations presented in Section 2.

Table 1. Geometrical properties of composite leaf spring.

\section{Geometry}

Span length $\left(\mathrm{L}_{\mathrm{s}}\right)$

Thickness (t)

Width at center (b)

Width at both ends

Free camber $\left(\mathrm{L}_{\mathrm{c}}\right)$

The 3D model of the leaf spring was first created by using Solidworks then imported into ANSYS Workbench to create finite element model. A total of 51040 SOLID 185 elements (having translations in $\mathrm{x}, \mathrm{y}$ and $\mathrm{z}$ directions) were used to create the FE model of leaf spring. The number of nodes was 60480. Through thickness, 20 elements were used in to order to get more accurate results. More refined mesh was used in the center of the leaf spring. Figure 3 shows the FE model of the leaf spring and applied boundary conditions. The both end of the spring were fixed in the $\mathrm{z}$-direction and the force $(\mathrm{P})$ with a magnitude of $10 \mathrm{kN}$ was applied in the $\mathrm{z}$-direction to the center of the mono-leaf spring. 


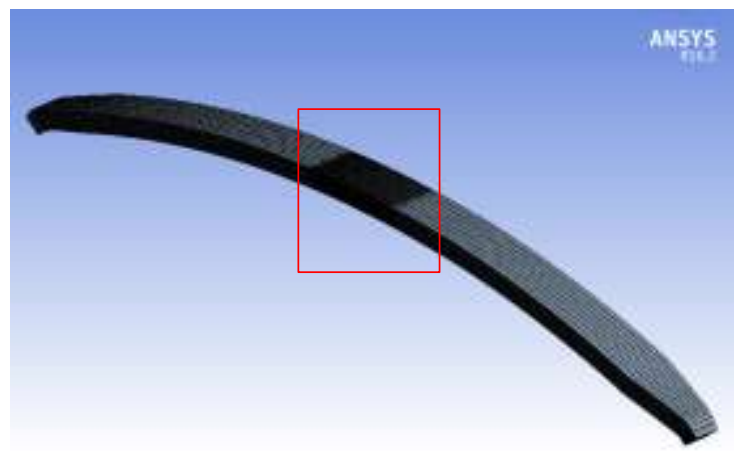

(a)

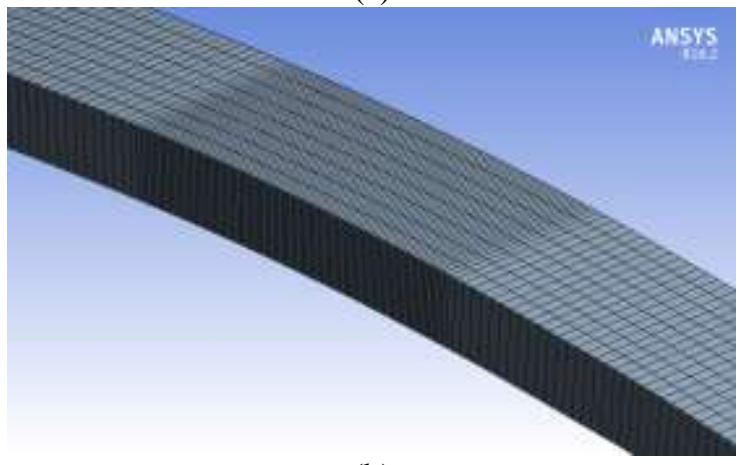

(b)

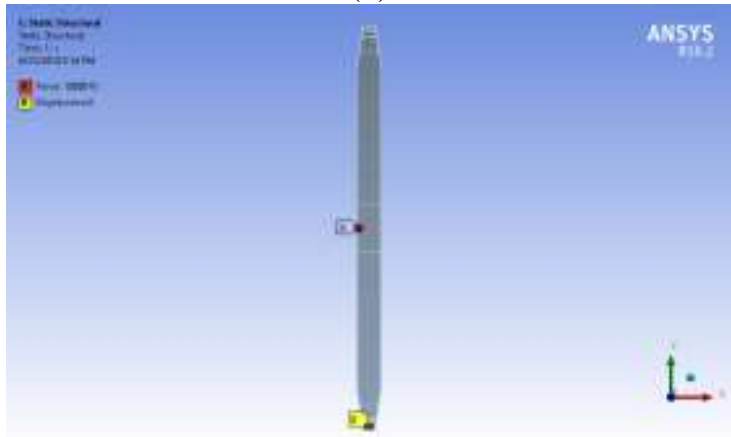

(c)

Figure 3. (a) Mesh structure, (b) a detailed view of mesh and (c) applied boundary conditions.

Figure 4(a) shows the directional deformation in the $y$ direction obtained by numerical analyses. The maximum displacement was determined as $12.125 \mathrm{~mm}$. As in the real-case bending test scenario, the both ends of the lead spring moved in the opposite direction of applied force. As can be seen in Figure 4(b-c), the maximum normal stress in the $y$ direction was determined as $264 \mathrm{MPa}$. As expected, the normal stress in the y-direction took its maximum and minimum values at the top and bottom of the spring, respectively. Because, these points were the farthest points from the neutral axis of the leaf spring.

Table 2 shows the comparison of numerical and analytical results for both deformation and stress values. The presented numerical values were obtained for the leaf spring under $10 \mathrm{kN}$ bending load. As can be seen, the numerical error was lower than $10 \%$. The numerical difference may be caused by the applied boundary conditions used in the numerical analyses. In the studies by Oztoprak et al. [13] and Sancaktar and Gratton [14], the numerical errors were between 5-7\%. The numerical errors were in the acceptable range considering these studies in the literature. Therefore, it could be said that the finite element model was confidently extended to the current study in which the effects of PU/CNTs nanoweb interlayers on the mechanical performance of the composite mono-leaf springs.

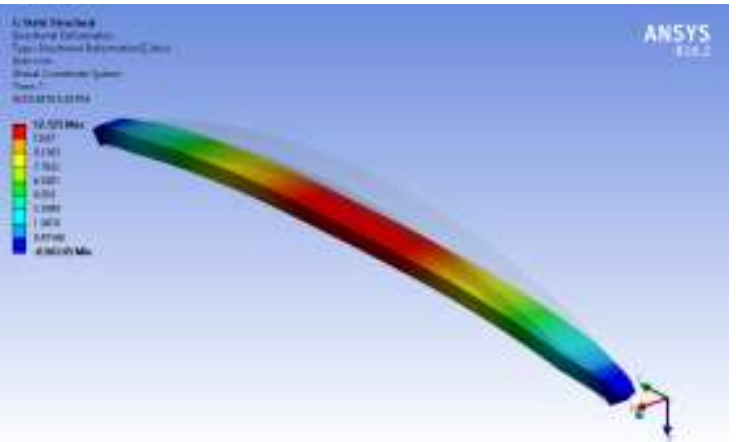

(a)

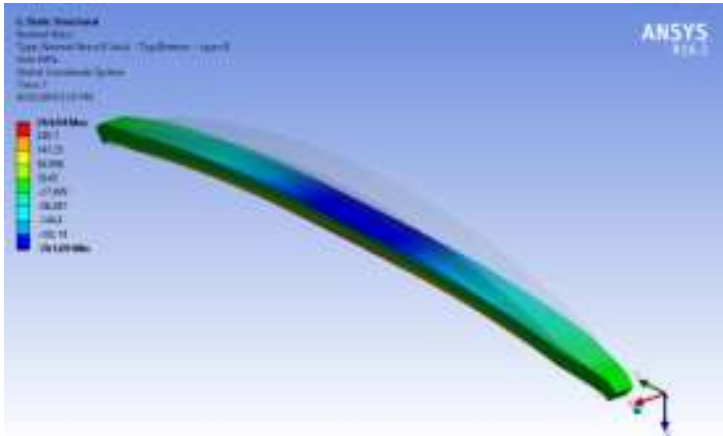

(b)

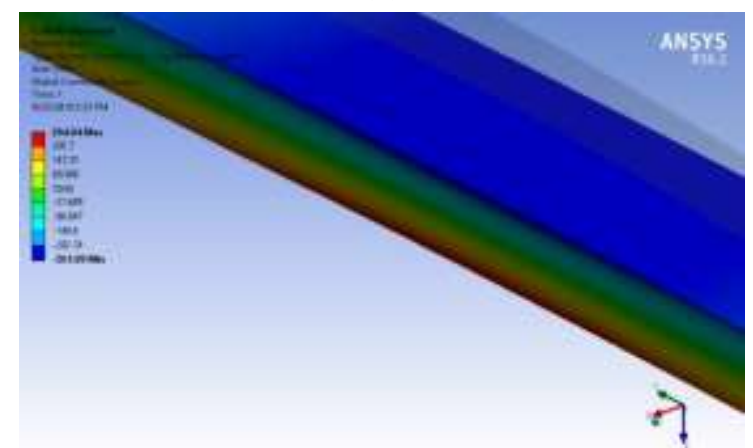

(c)

Figure 4. (a) Directional deformation in the z-direction, (b-c) the normal stresses in the y-direction occurred in the leaf spring.

Table 2. Comparison of analytical and numerical results.

\begin{tabular}{lccc}
\hline & Analytical & Numerical & \% error \\
\hline Deflection (mm) & 13.34 & 12.12 & 9.5 \\
Stress (MPa) & 287.3 & 264.0 & 8.4 \\
\hline
\end{tabular}


4. Finite element modeling of composite mono-leaf springs with PU/CNTs nanoweb interlayers

Table 3 shows the mechanical properties of $\mathrm{CF} / \mathrm{EP}$ composites with PU/CNTs nanoweb interlayers in the fiber and transverse directions. Liu et al. [15] stated that the PU/CNTs nanointerlayers had no significant effect on the Poisson's ratio (v) values of the composites.

Therefore, the Poisson's ratio was (v) kept constant. The density of the composite material with/without nanoweb interlayers was taken as $1490 \mathrm{~kg} / \mathrm{m}^{3}$ which can be found in ANSYS Workbench. These material data were directly used as material input in ANSYS Workbench.

Table 3. Mechanical properties of CF/EP composites with PU/CNTs nanoweb interlayers in the fiber and transverse directions [15].

\begin{tabular}{cccc}
\hline $\begin{array}{c}\text { CNTs } \\
\text { content } \\
(\mathbf{w t} \%)\end{array}$ & $\mathbf{E}_{\mathbf{1}}(\mathbf{G P a})$ & $\begin{array}{c}\mathbf{E}_{\mathbf{2}}=\mathbf{E}_{\mathbf{3}} \\
(\mathbf{G P a})\end{array}$ & $\begin{array}{c}\mathbf{v}_{\mathbf{1 2}}=\mathbf{v}_{\mathbf{2 3}}= \\
\mathbf{v}_{\mathbf{1 3}}\end{array}$ \\
\hline 0 & 115.1 & 9.12 & \\
1 & 128.1 & 10.15 & 0.311 \\
5 & 134.9 & 10.68 & \\
\hline $\begin{array}{c}\text { CNTs } \\
\text { content } \\
(\mathbf{w t} \%)\end{array}$ & $\mathbf{G}_{\mathbf{1 2}}=\mathbf{G}_{\mathbf{1 3}}$ & $\mathbf{G}_{\mathbf{2 3}}(\mathbf{G P a})$ & $\mathbf{v}_{\mathbf{1 2}}=\mathbf{v}_{\mathbf{2 3}}=$ \\
$\mathbf{v}_{\mathbf{1 3}}$ \\
\hline 0 & 5.67 & 3.48 & \\
1 & 6.31 & 3.87 & 0.311 \\
5 & 6.64 & 4.07 & \\
\hline
\end{tabular}

The thickness of each carbon fiber/epoxy ply was considered as $0.5 \mathrm{~mm}$. The total number plies were taken as 48 . The total thickness of the $\mathrm{CF} / \mathrm{EP}$ composite leaf springs without nanointerlayers was $24.0 \mathrm{~mm}$. The reason why a thickness of $24.0 \mathrm{~mm}$ was considered, will be explained in the following section. In nanoweb interleaved composite leaf springs, the PU/CNT nano interlayers were modeled as additional layers placed between two CF/EP layers. In total, the number of nanointerlayers was 47 (each nanoweb has a thickness of $0.02 \mathrm{~mm}$ ) in the composite leaf spring. The total thickness of the CF/EP composite leaf springs with PU/CNTs nanointerlayers was $24.94 \mathrm{~mm}$. Figure 5 shows the project schematic used for the numerical analyses of composite leaf springs. After the 3D geometric model was imported to ANSYS Workbench environment (Cell-A), the ply number, ply orientations and material properties were defined by using ACP Premodule (Cell-B).

Figure 6 shows the fiber direction in the composite leaf spring. Fibers were in the $0^{\circ}$ direction going through to the length of the spring. In this figure, green arrows indicate the fiber direction. As in the case of steel-made leaf spring, the SOLID185 element number was 51040 with 60480 nodes. The boundary conditions were also the same used for the analysis of steel-made leaf spring for comparison purposes. Static and modal analyses (Cells C and D) were carried to determine the effects of PU/CNTs nanoweb interlayers on the mechanical performance of composite mono-leaf springs. In modal analysis, only boundary conditions were applied, and no load was acted on the composite leaf spring.

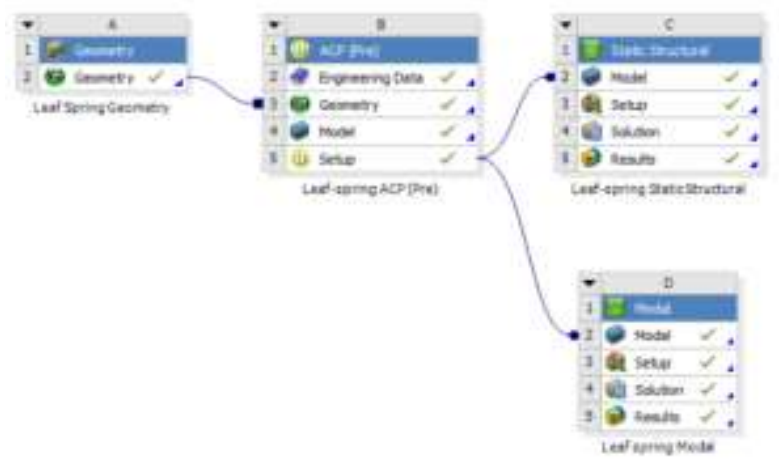

Figure 5. Project schematic of ANSYS Workbench.

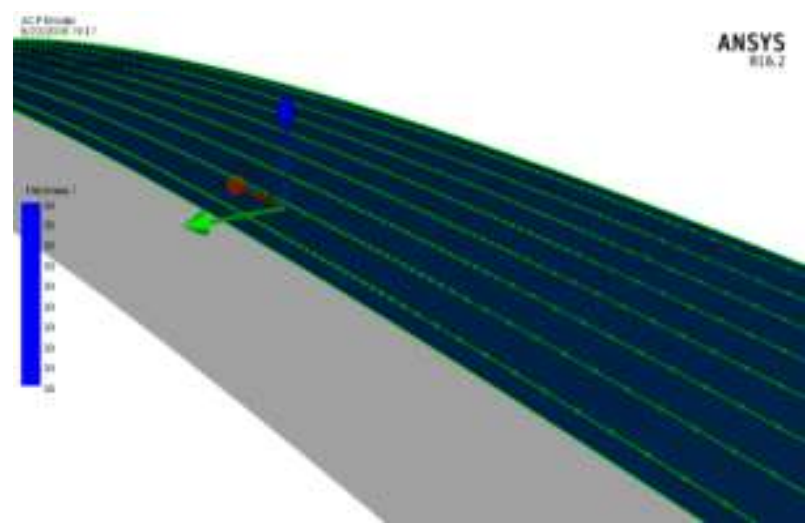

Figure 6. ANYS ACP-Pre module view.

\section{Results and Discussion}

\subsection{Steel leaf spring vs composite leaf spring}

In this section, a 4-wheeler commercial vehicle with a gross weight of $3500 \mathrm{~kg}$ was selected for the comparison of steel-made and CF/EP composite leaf springs without PU/CNTs nanointerlayers. The sprung weight of the vehicle was assumed as $3150 \mathrm{~kg}$ $\left(0.9 \mathrm{xW}_{\text {gross }}\right)$. The factor of safety was taken as 1.5 . The applied load to each wheel was calculated as $11588 \mathrm{~N}$ (1.5x3150x9.81/4). The minimum required leaf spring stiffness was considered as $200 \mathrm{~N} / \mathrm{mm}$. In the case of steel material, the required thickness to maintain this stiffness was calculated as $19.31 \mathrm{~mm}$ (approximately 20 $\mathrm{mm}$ ) using Equation (2.1). The weight of steel leaf spring was determined as $15.29 \mathrm{~kg}$. Figure 7 shows the directional deformation in the $\mathrm{z}$ direction. The maximum displacement was determined as $48.98 \mathrm{~mm}$. The corresponding stiffness of steel-made leaf spring was calculated as $236.58 \mathrm{~N} / \mathrm{mm}$. 


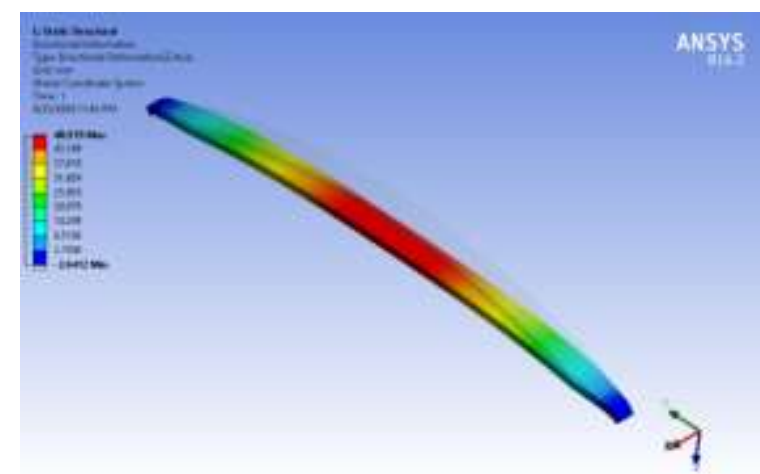

Figure 7. Directional deformation of steel leaf spring in the $\mathrm{z}$-direction $(\mathrm{t}=20 \mathrm{~mm}, \mathrm{P}=11588 \mathrm{~N})$.

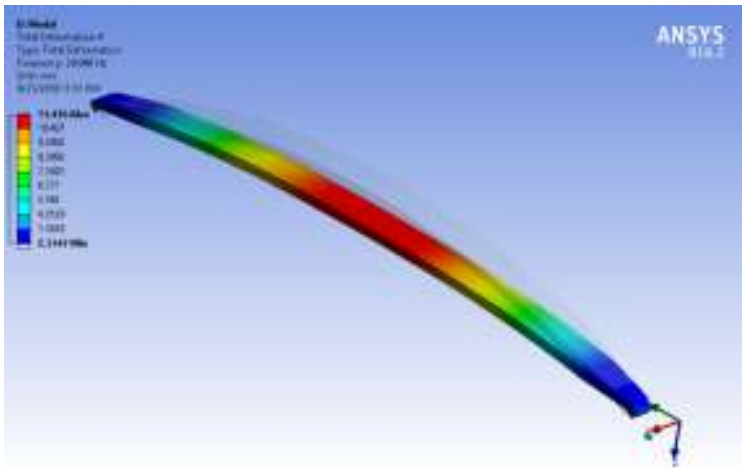

(a)

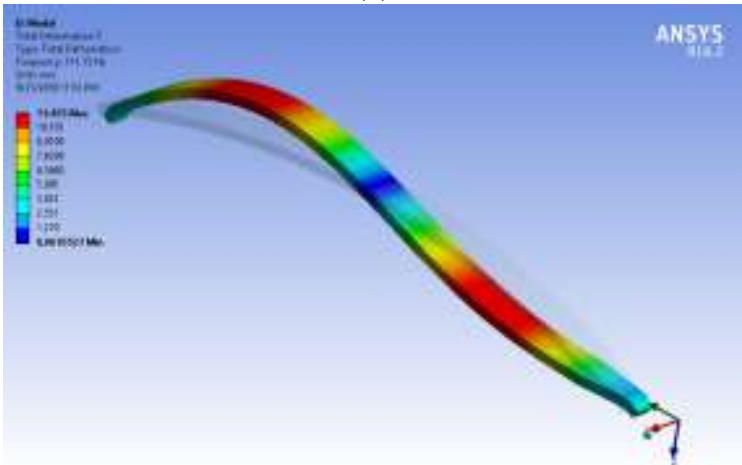

(b)

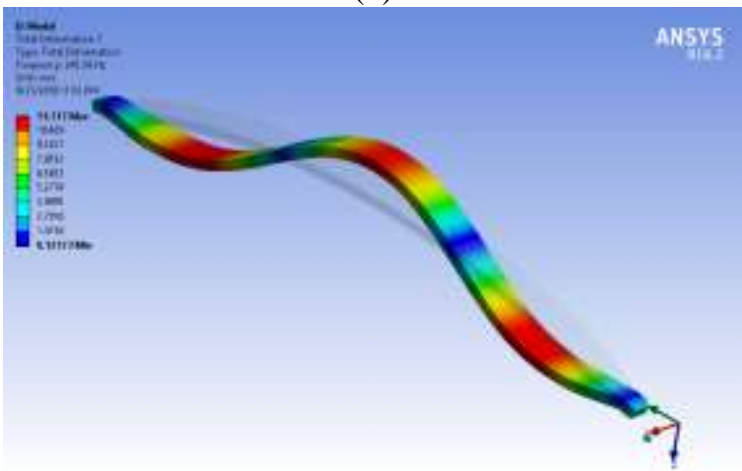

(c)

Figure 8. Mode shapes for steel leaf spring (a) $1^{\text {st }}$, (b) $2^{\text {nd }}$ and (c) $3^{\text {rd }}$ mode shapes.
Figure 8 shows the first three out-of-plane natural frequency modes of the steel leaf spring. The first, second and third natural frequency values were determined as 28.046, 111.13 and $245.38 \mathrm{~Hz}$, respectively. The frequencies induced by the road surface irregularities is generally less than $20 \mathrm{~Hz}$ [12]. The first mode natural frequency of the steel-made leaf spring was higher than this value which ensures the resonant condition was avoided. To obtain the minimum thickness of composite leaf spring which has the same stiffness that of steel-made leaf springs, parametric studies were carried out. Table 4 shows the maximum displacement and stiffness values of the composite leaf spring for different values of thickness. As can be seen, the stiffness values increased with the increase of thickness. In case of $24.0 \mathrm{~mm}$ thickness, the stiffness of composite spring $(236.38 \mathrm{~N} / \mathrm{mm})$ was almost equal to the stiffness of steel leaf spring $(236.58 \mathrm{~N} / \mathrm{mm})$. The weight of the composite leaf spring was $3.48 \mathrm{~kg}$. This value was almost 4.4 times lower than that of steelmade leaf spring $(15.29 \mathrm{~kg})$.

Table 4. Variation of maximum displacement and stiffness values for different composite leaf spring thickness.

\begin{tabular}{ccc}
\hline $\begin{array}{c}\text { Thickness } \\
(\mathbf{m m})\end{array}$ & $\begin{array}{c}\text { Maximum } \\
\text { displacement } \\
(\mathbf{m m})\end{array}$ & $\begin{array}{c}\text { Stiffness } \\
(\mathbf{N} / \mathbf{m m})\end{array}$ \\
\hline 22.5 & 59.72 & 194.02 \\
23.0 & 55.84 & 207.50 \\
23.5 & 52.28 & 221.60 \\
24.0 & 49.02 & 236.38 \\
25.0 & 43.26 & 267.86 \\
30.0 & 24.73 & 468.56 \\
\hline
\end{tabular}

Figure 9 shows the first three out-of-plane mode shapes extracted from the modal analysis of CF/EP composite leaf spring. The first, second and third natural frequency values of the $\mathrm{CF} / \mathrm{EP}$ composite leaf spring were determined as $58.88,230.64$ and $500.6 \mathrm{~Hz}$, respectively. Comparing these values with the natural frequencies of steel-made leaf spring, it could be noticed that the natural frequency values of composite leaf spring were much higher than those of steel-made spring. The outof-plane natural frequency values were almost two times higher than the steel leaf spring. The frequency values of composite leaf spring were much higher than the frequency value $(20 \mathrm{~Hz})$ which could cause resonance.

\subsection{Hybridization effect}

In this study, the effect of hybridization on the mechanical performance of composite leaf springs were also investigated. For this aim, E-glass fiber/epoxy composite plies were replaced with the carbon fiber/epoxy plies starting from the nearest plies to the 
neutral axis. Table 5 shows the mechanical properties of E-glass/epoxy composites. The stiffness values of the composite leaf spring were calculated after the replacement of E-glass fiber/epoxy composites. The thickness of the composite leaf spring was considered as $25 \mathrm{~mm}$ in this case. Parametric studies were carried out to determine the highest possible number of E-glass fiber/epoxy plies which provides the stiffness that of equal to the composite stiffness having a $24 \mathrm{~mm}$ thickness.

Table 5. Mechanical properties of E-glass /EP composites.

\begin{tabular}{ccccc}
\hline $\begin{array}{c}\mathbf{E}_{\mathbf{1}} \\
(\mathbf{G P a})\end{array}$ & $\begin{array}{c}\mathbf{E}_{\mathbf{2}}=\mathbf{E}_{\mathbf{2}} \\
(\mathbf{G P a})\end{array}$ & $\begin{array}{c}\mathbf{G}_{\mathbf{1 2}}=\mathbf{G}_{\mathbf{1 3}} \\
(\mathbf{G P a})\end{array}$ & $\begin{array}{c}\mathbf{G}_{\mathbf{1 3}} \\
(\mathbf{G P a})\end{array}$ & $\boldsymbol{v}_{\mathbf{1 2}}$ \\
\hline 45.0 & 10.0 & 5.0 & 3.84 & 0.3 \\
\hline
\end{tabular}

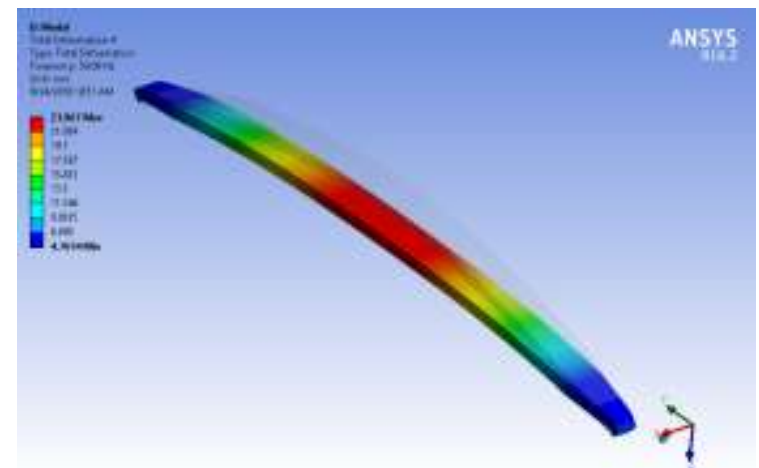

(a)

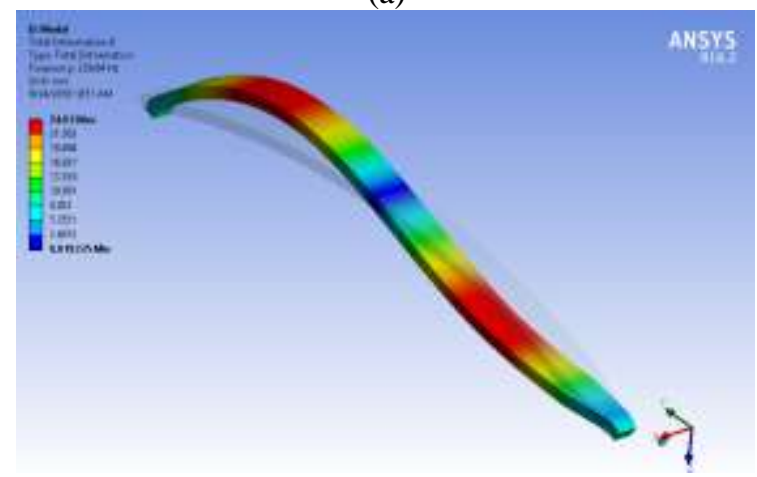

(b)

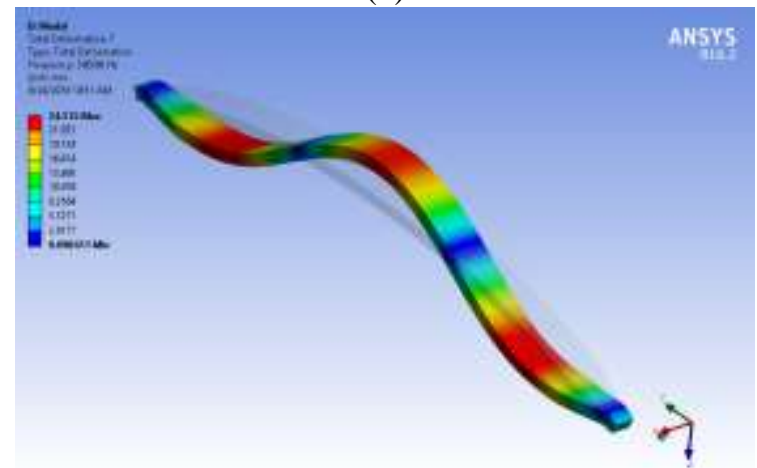

(c)

Figure 9. Mode shapes for composite leaf spring (a) $1^{\text {st }}$, (b) $2^{\text {nd }}$ and (c) $3^{\text {rd }}$ mode shapes.
Table 6 shows the hybridization on the stiffness and the weight of the composite leaf spring. The obtained stiffness was almost the same that of $24-\mathrm{mm}$ thick $\mathrm{CF} / \mathrm{EP}$ composite spring. Although the weight of the spring was increased from $3.48 \mathrm{~kg}$ to $4.35 \mathrm{~kg}$ after hybridization, the hybridization could reduce part weight 3.5 times compared to a steel leaf spring.

Table 6. Hybridization effect on the stiffness and weight of the composite leaf spring $(\mathrm{t}=25 \mathrm{~mm}$, Total number of plies $=50$ ).

\begin{tabular}{cccc}
\hline $\begin{array}{c}\text { Number of } \\
\text { carbon fabrics }\end{array}$ & $\begin{array}{c}\text { Number } \\
\text { of E-glass } \\
\text { fabrics }\end{array}$ & $\begin{array}{c}\text { Stiffness } \\
\text { (N/mm) }\end{array}$ & $\begin{array}{c}\text { Weight } \\
\text { (kg) }\end{array}$ \\
\hline 50 & 0 & 267.86 & 3.62 \\
40 & 10 & 266.51 & 3.87 \\
30 & 20 & 255.80 & 4.15 \\
26 & 24 & 247.34 & 4.25 \\
24 & 26 & 242.07 & 4.30 \\
22 & 28 & 236.0 & 4.35 \\
20 & 30 & 228.95 & 4.40 \\
\hline
\end{tabular}

5.3 Effect of PU/CNTs nanoweb interlayers on the stiffness and natural frequencies of composite leaf springs

In this section, the effects of PU/CNTs nanofibers on the mechanical performance of $\mathrm{CF} / \mathrm{EP}$ composite leaf springs were unrevealed.

Table 7 shows the stiffness of the reference and PU/CNTs nanoweb interleaved CF/EP composite leaf springs at different CNTs concentrations. Figure 10 shows the maximum displacement contours obtained for the nanoweb interleaved composite leaf springs. As can be seen, the incorporation of PU/CNT hybrid nanofibers between the carbon fiber/epoxy plies increased both stiffness and frequency values significantly. This is mainly due to the increased elastic modulus in the fiber direction. The bending stiffness matrix of the composite leaf spring increased after the addition of PU/CNTs nanofibers. The stiffness increased from $236.38 \mathrm{~N} / \mathrm{mm}$ to $262.88 \mathrm{~N} / \mathrm{mm}$ after the incorporation of PU/CNT nanofibers with $1 \mathrm{wt} \% \mathrm{CNT}$ content. This corresponds to an increase by $11 \%$. Also, with the increase in CNT content, the stiffness values continued to increase. The stiffness was increased from 262.88 to $277.05 \mathrm{~N} / \mathrm{mm}$ by about $18 \%$ in the case of PU/CNTs nanofibers at $5 \mathrm{wt} \%$ CNT concentration. It can be also concluded that thinner composite leaf springs could be used in suspension systems to obtain required stiffness by introducing PU/CNTs nanofibers in the interlaminar region. This will provide higher weight reduction comparing to the reference $\mathrm{CF} / \mathrm{EP}$ composite leaf springs. It is also important to note that the nanofibers in the interlaminar region reduces delamination risk by fiber bridging mechanism and increases the toughness of the composites. Also, as stated in the literature, these 
nanofibers have a positive effect on some other mechanical properties such as interlaminar shear strength and impact resistance. It is also noteworthy that the shear modulus of the composites increased after the addition of these nanofibers. The increase in shear modulus will have a positive influence on the mechanical response of nanofiber interleaved composites under torsion in return. As a result, the final product will be much more superior than the traditional composite leaf spring in terms of mechanical performance.

Table 7. Stiffness of CF/EP composite leaf springs with/without PU/CNTs nanoweb interlayers.

\begin{tabular}{|c|c|c|c|c|}
\hline $\begin{array}{c}\text { CNTs } \\
\text { content } \\
(w t \%)\end{array}$ & $\begin{array}{c}\text { Stiffness } \\
(\mathrm{N} / \mathbf{m m})\end{array}$ & $\begin{array}{c}\mathbf{1}_{(\mathrm{Hz})}^{\text {st }} \text { mode } \\
\text { a }\end{array}$ & $\begin{array}{c}2^{\text {nd }} \text { mode } \\
(\mathrm{Hz})\end{array}$ & $\begin{array}{c}3^{\text {rd }} \\
\text { mode } \\
(\mathrm{Hz})\end{array}$ \\
\hline 0 & 236.38 & 58.8 & 230.6 & 500.6 \\
\hline 1 & 262.88 & 62.0 & 243.2 & 527.5 \\
\hline 5 & 277.05 & 63.7 & 249.7 & 541.5 \\
\hline 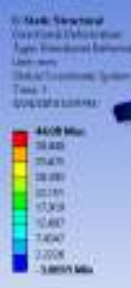 & & & & ANSYS \\
\hline
\end{tabular}

(a)

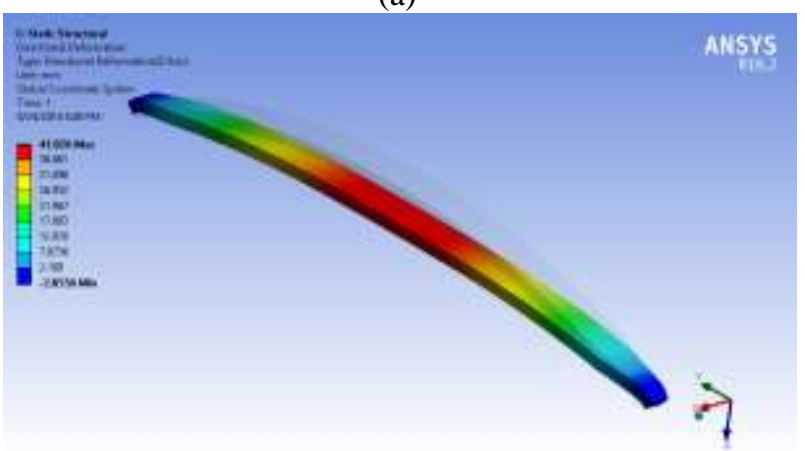

(b)

Figure 10. Maximum displacement contour obtained for the composite leaf spring interlaved by PU/CNTs nanofibers at (a) $1 \mathrm{wt} \%$ and (b) $5 \mathrm{wt} \% \mathrm{CNT}$ concentrations.

Table 7 also shows the natural frequency values of $\mathrm{CF} / \mathrm{EP}$ composite leaf springs with/without PU/CNTs nanofiber. As in the case of stiffness, an increasing tendency was also observed in the natural frequency values after the addition of PU/CNTs nanofibers. The frequency values increased with the increase of CNTs weight content took the maximum values when the CNTs content was reached to $5 \%$ by weight. The natural frequency values increased about $8.2 \%$ after the incorporation of these nanofibers as compared to reference $\mathrm{CF} / \mathrm{EP}$ composite leaf spring. Figure 11 shows the out-of-plane natural frequencies of the $\mathrm{CF} / \mathrm{EP}$ composites interleaved by PU/CNTs nanoweb interlayers with a $5 \mathrm{wt} \%$ CNTs content.

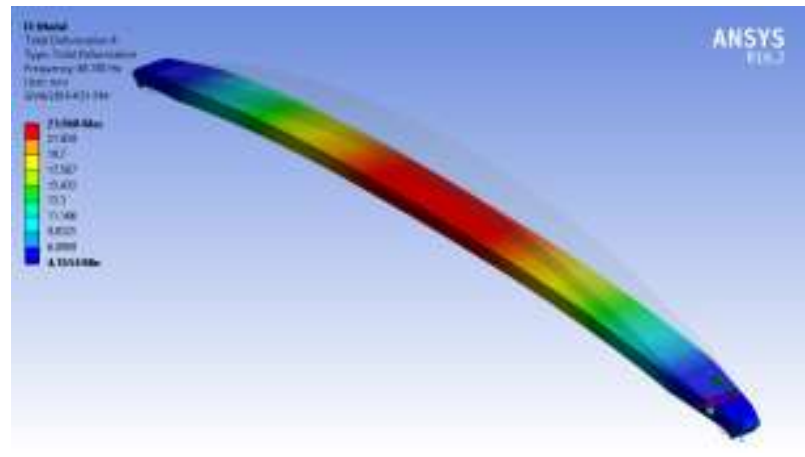

(a)

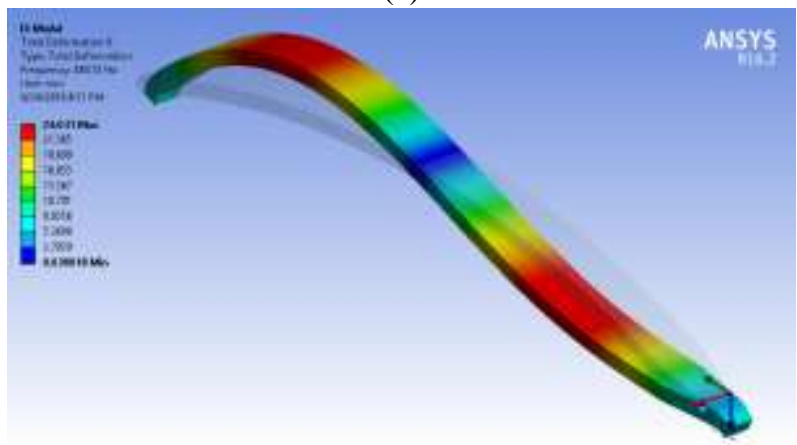

(b)

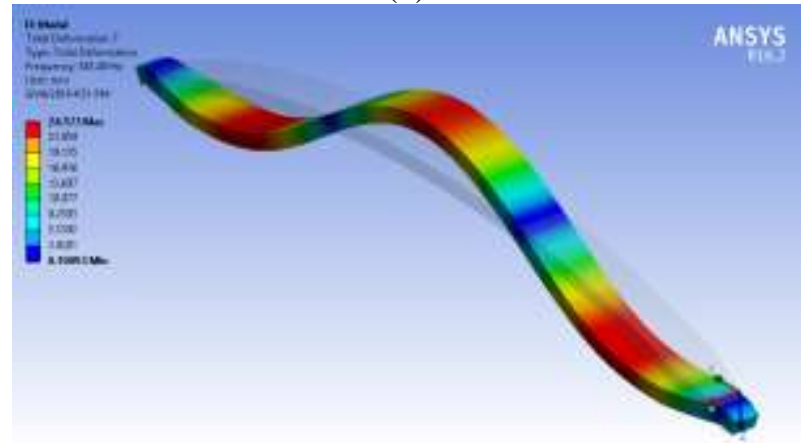

(c)

Figure 11. Mode shapes for composite leaf spring interleaved by PU/CNTs nanofibers at $5 \mathrm{wt} \%$ CNTs content (a) $1^{\text {st }}$, (b) $2^{\text {nd }}$ and (c) $3^{\text {rd }}$ mode shapes.

\section{Conclusion}

In this study, the effects of PU/CNTs nanofibers on the mechanical behavior of carbon fiber/epoxy composite leaf springs were investigated numerically. Numerical analyses were carried out by using ANSYS 16.2 software package. Numerical results were compared with the analytical ones for verification purposes. The numerical results were in good agreement with the 
Celal Bayar University Journal of Science

Volume 15, Issue 4, 2019 p 357-364

Doi: $10.18466 /$ cbayarfbe. 455110

analytical calculations. The main conclusions can be drawn from the present study as follows;

- PU/CNT interleaved composite leaf springs showed higher mechanical performance as compared to reference composite leaf springs without nanointerlayers.

- The stiffness and first mode natural frequencies increased with an increase in the CNTs content (from $1 \mathrm{wt} . \%$ to $5 \mathrm{wt} . \%$ ).

- The stiffness of the composite wave springs could be increased by $18 \%$ with the addition of PU/CNTs nanofibers (CNT content: 5 wt.\%) in the interlaminar region without weight and thickness increase.

- The natural frequency values increased by $8 \%$ after the addition of PU/CNT nanofibers (CNT content: 5 wt.\%).

- Hybridization can be used to reduce number carbon/epoxy plies (lower cost) without causing significant reduction in the required stiffness.

\section{Ethics}

There are no ethical issues after the publication of this manuscript.

\section{References}

1. Greenhalgh, ES, Rogers, C, Robinson, P, 2009. Fractographic observations on delamination growth and the subsequent migration through the laminate, Composites Science and Technology, 2009, 69(14), 2345-2351

2. Greenhalgh ES, Failure analysis and fractography of polymer composites, CRC Press, 2009, pp. 20-30.

3. Beylergil, B, Tanoglu, M, Aktas, E, 2017. Enhancement of interlaminar fracture toughness of carbon fiber/epoxy composites using polyamide 6/6 electrospun nanofibers, Journal of Applied Polymer Science, 2017, 134(35): 45244.

14. Sancaktar, E, Gratton, M, Design, analysis, and optimization of composite leaf springs for light vehicle applications, Composite Structures, 1999, 44(2-3), 195-204.

15. Liu, L, Zhang, H, Zhou, Y, Quasi-static mechanical response and corresponding analytical model of laminates incorporating with nanoweb interlayers, Composite Structures, 2014, 111, 436-445.
4. Jain A, Jindal A, Lakhiani P, Mishra S, Mathematical approach to helical and wave spring used in suspension system: A review, International Journal of Mechanical and Production Engineering, 2017, 5(6), 78-82.

5. Gaur N, Tripathi K, Kanchwala H, Analysis of load deflection characteristics of wave washer spring using 3D CAD modeling, International Journal of Applied Engineering Research, 2012, 7(13), 1525-1535.

6. Ashwini K, Mohan Rao CV, Design and Analysis of Leaf Spring using Various Composites - An Overview, Materials Today: Proceedings, 2018, 5(2), 5716-5721.

7. Zhang, H, Bharti, A, Li, Z, Du, S, Bilotti, E, Peijs, T, Localized toughening of carbon/ epoxy laminates using dissolvable thermoplastic interleaves and electrospun fibres, Composites Part A: Applied Science and Manufacturing, 2015, 79, 116-126.

8. Li, G, Li, P, Yu, Y, Jia, X, Zhang, S, Yang, X, Ryu, S, Novel carbon fiber/epoxy composite toughened by electrospun polysulfone nanofibers, Materials Letters, 2008, 62(3), 511-514.

9. Li, G, Li, P, Zhang, C, Yu, Y, Liu, H, Zhang, S, Jia, X, Yang, X, Xue, Z, Ryu, S, Inhomogeneous toughening of carbon fiber/epoxy composite using electrospun polysulfone nanofibrous membranes by in situ phase separation, Composites Science Technology, 2008, 68(34), 987-994.

10. Saghafi, H, Brugo, T, Minak, G, Zucchelli, A, The effect of PVDF nanofibers on mode-I fracture toughness of composite materials, Composites Part B: Engineering, 2015, 72, 213-216.

11. Beckermann, GW, Nanofiber interleaving veils for improving the performance of composite laminates. Reinforced Plastics, 2017, 61(5), 289-93.

12. Charde, RB, Bhope, BV, Investigation of stresses in master leaf of spring by FEM and its experimental verification, International Journal Engineering Science and Technology, 2012, 4(2), 633-640.

13. Oztoprak, N, Gunes, MD, Tanoglu M, Aktas E, Egilmez OO, Senocak C, Kulac G, Developing polymer composite-based leaf spring

systems for automotive industry, Science and Engineering of Composite Materials, 2018, 25(6), 1167-1176. 